\section{Criteria of Choice for R,D and D Support by the European Communities}

\author{
M. Paillon and C. White, Brussels \\ (Commission of the European Communities D.G. for Science, Research and Development; \\ Joint Research Centre)
}

It is a fundamental tenet of European Community involvement in science and technology that, in this field just as much as in economic affairs, the growing interdependence of States requires a corresponding increase in cooperation in scientific research and development.

The leaders of the European Community Member States had this very much in mind when, at a meeting of the European Council, in January 1974, they approved the principle of Community involvement in all fields of science and technology, except those affected by questions of military and industrial secrecy. This was the formal expression of a common policy which implied the coordination of national policies and the joint implementation of projects with a Community interest.

Community scientific activity had in fact built up from relatively modest beginnings in the earliest days of the Coal and Steel Community, dating from 1951. The treaty establishing this, and the Euratom treaty of 1958, reflected the preoccupation of those times with energy and raw materials. This preoc-

Table 1 - Community Research, Development and Demonstration Activities

1. Agriculture, Fish

1.1. Programmes for coordinating agricultural research

1.2 Coordinated action in the fisheries sector

2. Industry

2.1. B C R

2.1.1. Community Bureau of References

2.1.2. Community Bureau of References

2.2. Conventional technologies

2.2.1. Steel

2.2.2. High temperature materials

2.2.3. Textiles

2.2.4. Foodstuffs

2.3. New technologies

2.3.1. Bio technologies

2.3.2. Data processing

2.3.3. Data processing

2.3.4. Microelectronics

2.3.5. Remote sensing from space

3. Raw Materials

3.1. $R$ \& $D$ in the field of raw materials

4. Energy

4.1. Nuclear fission

4.1.1. Reactor safety

4.1.2. Safety of thermal water reactors

4.1.3. Safety of nuclear materials

4.1.4. Management and storage of radioactive waste

4.1.5. Fissile materials control and management

4.1.6. Support to safeguards

4.1.7. Plutonium fuels and actinide research

4.1.8. Nuclear measurements

4.1.9. Reactor development and advanced technologies

4.1.10. Operation of the HFR reactor

4.1.11. Decommissioning of nuclear power plants

4.2. Radioprotection

4.3. New forms of energy

4.3.1. Solar energy

4.3.2. Solar energy

4.3.3. Solar energy

4.3.4. Geothermal energy

4.3.5. Geothermal energy

4.3.6. Hydrogen production, energy storage and transport

4.3.7. Utilization of hydrogen

4.3.8. Systems analysis
4.4. Nuclear fusion

4.4.1. Controlled thermonuclear fusion

4.4.2. Thermonuclear fusion technology 4.4.3. JET

4.5. Coal

4.5.1. Mining methods Product upgrading

4.5.2. Gasification and liquefaction of solid fueis

4.6. Hydrocarbons

4.7. Energy conservation

4.7.1. R \& D programme

4.7.2. Demonstration project

5. Aid to developing countries

5.1.1. Science and technology for the benefit of developing countries

6. Health and safety

6.1. Medecine and public health

6.1.1. Cellular ageing

6.1.2. Etracorporeal oxygenation

6.1.3. Thrombosis. Hearing. Perinatal monitoring. Quantitative electrocardiography

6.1.4. Health problems. Health resources. Personal environment.

6.2. Hygiene and security

6.2.1. Effects on the health of workers of occupational hazards

6.2.2. Ergonomics and rehabilitation

6.2.3. Industrial hygiene in mines

7. Environment

7.1.1. Environmental protection

7.1.2. Environmental protection

7.1.3. Control of pollution in the iron and steel industry

7.1.4. Aids to coastal navigation

8. General interest activities

8.1.1. STID

8.1.2. Automatic translation

8.1.3. EUROTRA

8.1.4. Exploiting research results

8.1.5. FAST

8.1.6. Provision of scientific and technical services

8.1.7. Training

8.1.8. Scientific and technical education and training cupation was reinforced by the 1973 energy crisis, which gave added impetus to the development of alternative energy programmes. At the same time, research programmes were started which reflected the current concern over the harmonisation of norms and standards (in pursuance of a truly European market) and with protecting the environment.

In these areas, and particularly following the impetus given to Community research activities by the 1974 resolution, a great deal of valuable work has been done, much of it with a world-wide impact. To take one example, the efforts made in the field of new and renewable energy sources has acted as a stimulus and as a catalyst for national efforts. This is clearly the case in respect to solar energy, where the work which laid the bases for cooperation between industrial companies and collaboration between laboratories gave the Member States of the European Community the opportunity to acquire a scientific and technical capability in the field more quickly than if they had had to rely on isolated or dispersed initiatives. The same is true also of the fusion programme, where the Member States are working together for long term benefits, which are equally appreciated by the several non-Member States now involved. In the Joint European Torus JET, the Community has a facility of world class, whose promise has been confirmed by the successful (and earlier than scheduled) start-up in June and the recent discharge currents approaching 1.5 MA. Again, the various programmes in the field of nuclear fission, such as those dealing with reator safety, the management and storage of radioactive waste products, the control of fissile materials and radioprotection, together constitute a joint response to many problems which the Member States have in common. The quality and scope of the programmes put the Community in a good position for international cooperation, as has been underlined by treaties signed with the IAEA, the United States and Canada.

On a different front, the work that has been done on norms and standards by the Community's Central Bureau for Nuclear Measurements and by the Community Reference Bureau has gained widespread recognition, and has emphasised the need to undertake specific actions (for example on reference materials and techniques) and to provide a public service for laboratories and for European industry.

Despite the value and effectiveness of the programmes and the coordination 
which had, up till 1980, been carried out at Community level (see Table 1), the feeling had been growing, reinforced by a series of analyses undertaken by experts on the Community's behalf, that a reorientation of the Community's scientific and technical strategy was necessary if it was to make a sufficient response to the challenges posed by the 1980s.

In particular, it was evident that the Community could not follow a policy that exactly mirrored those adopted by each of its Member States, and that research and development activities that are the subject of a joint entreprise must fulfil the conditions of possessing not only general interest, but also of being intrinsically suited to a cooperative approach.

In 1981 therefore, the Commission put forward to the Member States a plan for a consistent development of its science policy during the 1980 s based on a number of clearly defined scientific and technical objectives.

\section{Choice of Objectives}

Four general criteria govern the choice of overall scientific and technical objectives:

$$
\begin{aligned}
& \text { - competitiveness } \\
& \text { - independence } \\
& \text { - solidarity } \\
& \text { - progress. }
\end{aligned}
$$

The scientific and technical policy adopted has to satisfy these four conditions, which are essentially of a political nature. In a global market where competition is the rule, the Community must seek especially to promote competitiveness in the principal market sectors such as agriculture or industry. Science and technology can make an important contribution in this respect. Every effort must be made to reduce the growing dependence of the Community on external suppliers, particularly in regard to raw materials and energy, where the distribution of resources is so uneven.

In an increasingly interdependent world, the Community must not only recognise the problems of the developing countries, but should also demonstrate its solidarity with them. At the same time, sight must not be lost of the principal aim of the Community, which is to improve the standards of living and working of its peoples. Science and technology must therefore contribute not only to the pool of knowledge but also to raising the quality of life and employment.

Whilst these overall political aims must be satisfied, an increased effort is also needed to make the best of the immense and varied scientific and technical potential in the Member States, and to develop it.

Thus, the Commission has proposed the following detailed criteria for use in the selection of specific scientific and technical objectives:

\section{- Extent of Financial and Manpower} Needs

The effort involved must be greater than can conveniently be mobilised on a national basis. An example is the development of thermoculear fusion which, in the long term, should decrease the energy dependence of the Community on external suppliers. The resources necessary to achieve this objective, both in human and money terms are beyond the means of an individual country, and cooperation on at least the European scale is obligatory.

\section{- Market Potential}

This relates to the size of the eventual market or its organization. An illustration is the development of new information technologies and the associated market problems which have become acute. A lack of cooperation and the individualistic research of European companies in many cases in the past (colour TV for example) resulted in the fragmentation of the market to the disadvantage of all, whereas some harmonisation or standardisation prior to marketing, would have brought obvious benefits. The policies adopted in Japan and the USA are worth recalling in this context.

Further, developments in these technologies, because of the size and variety of demand, call for a research and production effort in the scientifically developed countries that is considerable. Performance and reliability as well as cost are prime factors in maintaining competitivity at an international level. The investments needed both now and in the future to introduce a new product are of such a magnitude that, at the minimum, a European scale market is required, especially if a successful attempt is to be made in attacking world markets.

\section{- Transnationality}

Activities need to be essentially international in nature, a notable example being environmental protection which has particular relevance to the Treaty objective of improving the quality of life. Many actions related to the environment or damage prevention can only be realised as a cooperative venture. It is evident that, as Member States have recently recognised, complex processes such as the degradation of forests must be analysed and tackled in a European, not to say an

\section{New Members of the European Physical Society}

\section{Category 4a)}

A.A.-E.-K. Ammar, Shebin-El-Koom, Egypt

M. Bornatici, Pavia, I

J. Rem, Nieuwegein, NL

\section{Category 4c)}

Belgian Physical Society

M. Godefroid, Brussels

\section{Danish Physical Society \\ K.M. Jensen, Kokkedal \\ $\mathrm{H}$. Lauritzen, Odense \\ N.I. Meyer, Lyngby}

Eötvös Lorand Physical Society P. Ribarics, Budapest

\author{
Finnish Physical Society \\ J. Alanen, Tampere \\ R. Anttila, Oulu \\ H. Kurki-Suonio, Austin, USA \\ A. Pakkanen, Jyväskylä \\ O. Ranta, Espoo \\ J. Routti, Helsinki \\ H. Sipilä, Espoo
}

French Physical Society

L. Harmel, Quievrain, B

B. Jacrot, Grenoble

German Physical Society

J. Treusch, Dortmund

G. von Minnigerode, Göttingen
Hellenic Physical Society

P. Euthymiou, Athens

E. Hatzikraniotis, Thessaloniki

C. Papastefanou, Thessaloniki

K. Paraskevopoulos, Thessaloniki

S. Patapis, Athens

Icelandic Physical Society

E.H. Gudmundsson, Reykjavik

The Institute of Physics

D.A. Darbyshire, Northwood

A.Y.W. Ng, London

Italian Physical Society

M. Asdente, Milan

R. Bruzzese, Naples

M. Giglio, Milan

M. Messerotti, Trieste
Polish Physical Society

H. Kozlowski, Wroclaw

M. Nowak, Gliwice

M. Przytula, Lodz

Spanish Royal Society of Phy sics

A.M. Gomez, Madrid

Turkish Physical Society

A. Gökalp, Ankara

\section{Category 4d)}

(American Physcial Society)

J.M. Hauptman, Ames, IA

N. Jarmie, Los Alamos, NM

C.R. Jones, Durham, NC

A. Karipidou, Cambridge, MA

E. Mravlag, Grahamstown, SA

P. Murray, Dayton, $\mathrm{OH}$

A. Osman, Cairo, Egypt

J. Rufinus, Jakarta, Indonesia

G.M. Temmer, Piscataway, NJ

W. Walters, College Park, MD 
international, context if appropriate solutions are to be found.

\section{- Collective Needs}

These relate to objectives that are similar in a number of countries, justifying a common approach as much to avoid wasteful duplication as to promote a harmonisation of projects and methods. The support for nuclear power and the improvements of safety standards in power stations are obvious examples.

All these criteria, which have been applied to the objectives selected for the 1984-87 Framework Programme (Table 2) are a reflexion of the Community's major preoccupation, which is to exploit Europe's size and diversity in an effective and relevant manner. Community level action is the logical answer to problems such as sharing the risks and costs of the largest investments, assuring the necessary stability and continuity of action, or avoiding dangerous set-backs in highly advanced research.

\section{The Framework Programme}

At its meeting on 28 June 1983 the Council of Research Ministers adopted the principle of a Framwork Programme for the first time. It will apply initially to the years 1984-1987 and, in its essentials, it endorses the criteria already outlined. As a reflexion of these criteria and the Community's overall scientific objectives, the Commission has divided its $R$, D \& D activities into appropriate groups, and identified what changes of priority should apply to each. Action programmes within these groups of activities will be required to satisfy common interests and comply with the Community's budgetary constraints. The criterion of common interest is interpreted as requiring all the Member States to participate for the general good in at least part of the programme according to their means. Overall there should be a balance between participants in a given field. The second criterion stipulates that the Community must stay within its means.

Specific projects will be selected by the Commission, aided by relevant management committees, from proposals submitted in reply to public invitations published in the Official Journal. They will be evaluated according to their scientific and technical value, their chance of success and the prospects for application. The opportunity for cooperation between several laboratories in the Member States will also be taken into consideration, each project being required to involve a majority of the Members to guarantee its interest to the community. The laboratories concerned can be either industrial or public. As to cost, this must be high enough to ensure that the effort is above the threshold level, but the figure will depend greatly on the field. Thermonuclear fusion projects, for example, will in general be more costly than those in medical research.

Finally, continuation of a programme will be dependent on the results obtained, to which the Commission will apply the following supplementary tests:

- progress made towards the goal at which the project is aimed,

- scientific and technical or socioeconomic interest of the results obtained, measured especially by the patents taken out or papers published,

- stimulation or training value to other Community $R$ \& D projects,

- level and manner in which ressources have been used.

\section{Conclusions}

Although the Community has 20 years experience in programming $R, D$ \& $D$ activities, this is not the case for the application of the Framework Programme nor the implementation of the defined science and technical policy. It has to be seen whether in practice the criteria adopted give the results that are looked for. But in any case, it has to be recognised that the programme is at the mercy of political choices and budget decisions, the availability of resources being as always the determinant factor.

Table 2 - Correlation Between Criteria and Objectives

1 = Main correlation

2 = High degree of correlation

3 = Secondary correlation

1. Promoting agricultural competitiveness

- Developing agricultural productivity and improving products: agriculture fisheries

2. Promoting industrial competitiveness - Removing and reducing hindrances

- New techniques and new products for conventional industries

- New technologies

3. Improving Management of Raw Materials

4. Improving the Management of Energy Resources

- Development of nuclear fission energy

- Controlled thermonuclear fusion

- Development of renewable energy sources

- Rational use of energy

5. Reinforcing development aid

6. Improving Living and Working Conditions - Improving Safety \& protecting Health - Protecting the Environment

7. Improving the efficacy of the Community's scientific \& technical potential

\section{University of Manchester}

Department of Physics

\section{Postdoctoral Research Associate in Experimen- tal Nuclear Structure Physics}

Applications are invited for the above post which is now vacant and is funded by the SERC for the period until 31 January, 1987. The successful candidate will be expected to initiate and assist with research at the Nuclear Structure Facility, a 20/30 MV tandem van de Graaff, which is now operational at the Daresbury Laboratory. Exploitation of the on-line isotope separator at Daresbury Laboratory will also form a part of the candidate's duties.

Applicants are expected to hold a Ph.D. degree in Nuclear Structure Physics and should have an aptitude for pursuing research in experimental physics. Salary range $£ 7190-£ 8530$ p.a. (Superannuation). Applications, with full C.V. and names of two referees to:

Dr. R. Chapman,

Department of Physics,

The University, Manchester MI3 9PL

from whom further details may be obtained.

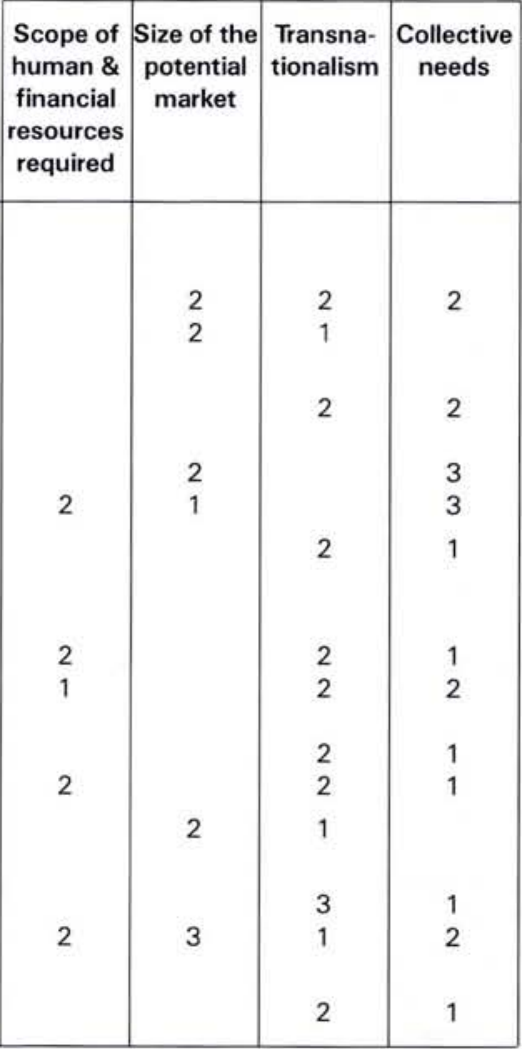

